RAMALHO JUNIOR, Elmir Duclerc. Ensaio para uma teoria agnóstica do processo penal. Revista Eletrônica Direito e Política, Programa de Pós-Graduação Stricto Sensu em Ciência Jurídica da UNIVALI, Itajaí, v.10, n.2, $1^{\circ}$ quadrimestre de 2015. Disponível em: www.univali.br/direitoepolitica - ISSN 1980-7791.

\title{
ENSAIO PARA UMA TEORIA AGNÓSTICA DO PROCESSO PENAL
}

\author{
ESSAY FOR AGNOSTIC THEORY OF CRIMINAL PROCEDURE
}

\author{
Elmir Duclerc Ramalho Junior ${ }^{1}$
}

SUMÁRIO: Introdução. 1. O papel de uma teoria do processo penal, nos limites entre filosofia, ciência e técnica. 2. Pressupostos filosóficos para uma teoria do processo penal (ou: por que uma teoria agnóstica). 3. Dos pressupostos científicos de uma teoria agnóstica do processo penal (ou: por que uma teoria do processo penal). 4. Teoria agnóstica do processo penal e técnica: algumas questões relacionadas ao regime de ação, jurisdição e processo. 4.1. Teoria agnóstica e ação. 4.2. Teoria agnóstica e processo. 4.3. Teoria agnóstica e jurisdição. 5. Teoria agnóstica e método de ensino do direito processual penal. Considerações finais. Referências das fontes citadas.

RESUMO: O trabalho pretende investigar as condições de possibilidade para a construção de uma teoria do processo penal, totalmente independente de qualquer teoria geral do processo, como tronco comum genérico aplicável a diversas espécies. Para tanto, a pesquisa se desdobra em etapas ou que correspondem, respectivamente, aos pressupostos filosóficos e científicos de uma tal teoria, mas avança também sobre as suas principais implicações no plano da técnica processual penal, bem como no plano do próprio método de ensino da disciplina. Ao final, fica demonstrada a conveniência e a necessidade de construção dessa teoria, a partir de uma concepção agnóstica, ou negativa de pena criminal, isto é, que recusa à pena qualquer justificação racional, e exige, pois, a formulação de conceitos operativos próprios e adequados a essa premissa.

Palavras-chave: Processo Penal; Garantismo Penal; Criminologia Crítica; Teoria Agnóstica.

\footnotetext{
1 Promotor de Justiça Criminal em Salvador, Bahia, Brasil. Doutor em Direito pela Universidade Estácio de Sá (UNESA). Mestre em Ciências Criminais pela Universidade Cândido Mendes (UCAM). Professor de Direito Processual Penal da Universidade Federal da Bahia (UFBA). Membro Fundador e Ex-Presidente do Instituto Baiano de Direito Processual Penal (IBADPP). E-mail: elmir.duclerc@gmail.com.
} 
RAMALHO JUNIOR, Elmir Duclerc. Ensaio para uma teoria agnóstica do processo penal. Revista Eletrônica Direito e Política, Programa de Pós-Graduação Stricto Sensu em Ciência Jurídica da UNIVALI, Itajaí, v.10, n.2, $1^{\circ}$ quadrimestre de 2015. Disponível em: www.univali.br/direitoepolitica - ISSN 1980-7791.

ABSTRACT: The paper aims to investigate the conditions of possibility for the construction of a theory of criminal procedure, totally independent of any general theory of procedure, as a general common core applicable to different species. Therefore, the research unfolds in stages corresponding, respectively, to philosophical and scientific assumptions of such a theory, but also advances on its main implications in terms of criminal procedural technique as well as on the level of discipline of teaching method itself. In the end, it demonstrates the convenience and the need to build this theory, from an agnostic design, or denial of criminal penalty, that is, refusing the punishment any rational justification, and therefore calls for the formulation of proprietary operating concepts and appropriate to this assumption.

Keywords: Criminal Procedure; Criminal Guaranteeism; Critical Criminology; Agnostic Theory.

\section{INTRODUÇÃo}

O texto que segue, como o título já anuncia, pretende ser apenas um ensaio para uma Teoria Agnóstica do Processo Penal. Ou seja, é o registro do estado da arte de um trabalho em construção, em torno de uma inquietação que já há algum tempo me persegue, e que é compartilhada por muitos dos que militam por um processo penal democrático no Brasil. Portanto, o estudo busca apresentar algumas intuições iniciais que pretendemos aprofundar e por à prova oportunamente, mas, desde já, expor ao debate. Foi produzido no ambiente e a partir dos estudos realizados pelo Grupo de Pesquisa Transdisciplinar em Processo e Ciências Criminais, que coordeno na Universidade Federal da Bahia. Não poderia, portanto, deixar de agradecer aos meus orientandos, especialmente, nesse trabalho, a Gabriela Andrade, pela interlocução e prestimosa ajuda na formatação.

Os dicionários de filosofia mais festejados apontam pelo menos quatro sentidos diferentes em que a expressão teoria é comumente utilizada. De todos eles, para os fins do presente trabalho, interessa-nos especificamente aquele que a identifica como uma hipótese, ou como um conjunto de hipóteses articuladas entre si e vertentes sobre um determinado objeto ou área do saber humano. Mas não é necessariamente um modelo de explicação de fatos, senão um instrumento de classificação e previsão. A sua verdade, pois, decorre de sua validade, assim 
RAMALHO JUNIOR, Elmir Duclerc. Ensaio para uma teoria agnóstica do processo penal. Revista Eletrônica Direito e Política, Programa de Pós-Graduação Stricto Sensu em Ciência Jurídica da UNIVALI, Itajaí, v.10, n.2, $1^{\circ}$ quadrimestre de 2015. Disponível em: www.univali.br/direitoepolitica - ISSN 1980-7791.

entendida como capacidade de cumprir as funções a que se destina. Para tanto, deve ser capaz de construir um esquema de unificação sistemática de conteúdos diversos (grau de abrangência). De igual modo, deve oferecer um conjunto de meios de representação conceitual e simbólica dos dados de observação, conforme um critério de economia dos meios conceituais (simplicidade lógica).

No âmbito do saber jurídico, em todas as suas dimensões, há uma miríade de teorias sobre toda sorte de temas, dos mais específicos aos mais gerais, algumas de cunho mais operacional, e outras de viés claramente especulativo, culminando, inclusive, com as teorias (especulativas) do direito que perseguem a essência do próprio fenômeno jurídico, e com uma teoria geral do direito, inspirada, como se sabe, pela pretensão de uniformização do instrumental conceitual a ser utilizado transversalmente nas diversas áreas da dogmática jurídica.

É nessa última perspectiva que pretendo desenvolver o trabalho, refletindo, primeiro, sobre as condições de possibilidade de uma teoria do processo penal totalmente desvinculada de qualquer teoria geral do processo, contrariando, portanto, uma tradição de pensamento muito difundida, atualmente, sobretudo entre os amantes do Direito Processual Civil, e consagrada em muitas grades curriculares de cursos de Direito em todo o Brasil.

Segundo minhas intuições iniciais, ademais, a questão posta no parágrafo anterior demanda também uma pergunta fundamental sobre as funções de uma tal teoria, isto é, sobre o que dela se pode esperar como ferramental tecnológico que auxilie da melhor forma o operador do direito na difícil tarefa de decidir conflitos penais, na atual quadra da história e na perspectiva do moderno Estado Democrático de Direito.

Nessa linha de raciocínio, desde já antecipo que, para enfrentar as questões, ou conjunto de questões postas acima, parto de duas hipóteses que pretendo explorar, ainda que de forma incipiente, como se pode esperar de um ensaio. Tais seriam: a) A luta por um direito processual penal democrático, no Brasil, demanda de forma urgente a construção de uma teoria do processo penal desvinculada de qualquer noção de teoria geral do processo; b) Para bem 
RAMALHO JUNIOR, Elmir Duclerc. Ensaio para uma teoria agnóstica do processo penal. Revista Eletrônica Direito e Política, Programa de Pós-Graduação Stricto Sensu em Ciência Jurídica da UNIVALI, Itajaí, v.10, n.2, $1^{\circ}$ quadrimestre de 2015. Disponível em: www.univali.br/direitoepolitica - ISSN 1980-7791.

cumprir as suas funções, uma tal teoria deve estar assentada numa concepção radicalmente crítica da própria intervenção penal do Estado, dentro de uma sociedade que se pretenda civilizada, o que pressupõe uma concepção agnóstica da pena, nos moldes de Zaffaroni.

Enfrentar essas questões implica uma revisão dos pressupostos filosófico-críticos e propriamente científicos de uma tal teoria, o que nos deixará no ponto ótimo para uma revisão, também, de determinadas categorias conceituais que herdamos do direito processual civil, a fim de construir um ferramental tecnológico próprio, ainda que seja necessário romper drasticamente com essa tradição.

\section{O PAPEL DE UMA TEORIA DO PROCESSO PENAL, NOS LIMITES ENTRE FILOSOFIA, CIÊNCIA E TÉCNICA}

Como registra Marilena Chauí, a primeira perplexidade encontrada por quem pretende estudar filosofia tem a ver com a aparente impossibilidade de encontrar uma única definição que consiga abarcar todas as suas características ${ }^{2}$.

Para Abbagnano ${ }^{3}$, entretanto, a disparidade de significações que o próprio termo filosofia assumiu ao longo da história não impede que sejam apontadas algumas constantes que permitam identificar em que medida um determinado texto pode aspirar a ser reconhecido como produto de reflexão autenticamente filosófica. Fragmentos do Eutidemo de Platão sugerem, de fato, que a filosofia, desde a Antiguidade, era entendida como o uso do saber em proveito do homem. Desse conceito bastante sintético, ademais, seria possível extrair os seguintes traços essenciais do pensamento filosófico: a) a posse ou aquisição de um conhecimento que seja, ao mesmo tempo, o mais válido e o mais amplo

\footnotetext{
2 CHAUÍ, Marilena. Convite à filosofia. 13. ed. São Paulo: Ática, 2009, p. 22-23. Haveria, assim, pelo menos quatro grandes definições com pretensões de universalidade, nesses termos: a) visão de mundo; b) sabedoria de vida; c) esforço racional para conceber o universo como uma totalidade ordenada e dotada de sentido; d) fundamentação teórica e crítica dos conhecimentos e das práticas.

${ }^{3}$ ABBAGNANO, Nicola. Dicionário de filosofia. 3. ed. São Paulo: Martins Fontes, 1999, p. 442456.
} 
RAMALHO JUNIOR, Elmir Duclerc. Ensaio para uma teoria agnóstica do processo penal. Revista Eletrônica Direito e Política, Programa de Pós-Graduação Stricto Sensu em Ciência Jurídica da UNIVALI, Itajaí, v.10, n.2, $1^{\circ}$ quadrimestre de 2015. Disponível em: www.univali.br/direitoepolitica - ISSN 1980-7791.

possível; e, b) o uso desse conhecimento em benefício do homem. Esses dois elementos, que podem ser identificados nas obras fundadoras da filosofia ocidental, vêm sendo reafirmados sistematicamente ao longo da história, ainda que com pequenas variações (como se vê, por exemplo, em Kant, Dewey e Wittgenstein ${ }^{4}$ ).

Para uma primeira aproximação da distinção e dos limites entre filosofia, ciência e técnica, entretanto, importa pensar esses traços essenciais à luz de uma concepção de filosofia como fundamentação teórica e crítica dos conhecimentos e das práticas, uma busca que demandaria, acima de tudo, análise, reflexão e crítica $^{5}$, laborando juntas para construir filosoficamente as ideias gerais sobre a realidade e os seres humanos.

Pode-se dizer, portanto, que embora não seja ciência, a filosofia "é uma reflexão sobre a ciência"; embora não seja sociologia nem psicologia, se apresenta como "avaliação crítica dos conceitos e métodos da sociologia e da psicologia"; que embora não se confunda com a política, consiste em "interpretação, compreensão e reflexão sobre a origem, a natureza e as formas do poder e suas mudanças"; por fim, que mesmo não sendo história, implica uma "reflexão sobre o sentido dos acontecimentos enquanto inseridos no tempo e compreensão do que seja o próprio tempo" ${ }^{6}$.

Mas o que seria mesmo ciência? De um modo geral, a ciência tem sido definida por oposição ao senso comum, como forma específica de conhecimento que inclui em qualquer forma ou medida uma garantia da própria validade ${ }^{7}$.

\footnotetext{
${ }^{4}$ ABBAgnANO, Nicola, Dicionário de filosofia, p. 442. Como explica Abbagnano, ademais, na "Crítica da razão pura", Kant define o conceito cósmico da filosofia (o conceito que interessa necessariamente a todos os homens) como o de "ciência da relação do conhecimento à finalidade essencial da razão humana". Essa finalidade essencial é a "felicidade universal". Portanto, a filosofia "refere tudo à sabedoria, mas através da ciência". Para Dewey, a filosofia seria a "crítica dos valores", no sentido de "crítica das crenças, das instituições, dos costumes, das políticas, no que se refere seu alcance sobre os bens" (Experience and nature, p. 407). Por seu turno, Wittgenstein afirma que o propósito da filosofia é levar ao desaparecimento dos problemas filosóficos, eliminando a própria filosofia, ou se "curar" dela.

${ }^{5}$ CHAUÍ, Marilena, Convite à filosofia, p. 23.

${ }^{6}$ CHAUÍ, Marilena, Convite à filosofia, p. 23

7 Assim, por exemplo, CHAUÍ, Marilena, Convite à filosofia, p. 216-218, e também ABBAGNANO, Nicola, Dicionário de filosofia, p. 136, referindo-se à superioridade da ciência em face da opinião.
} 
RAMALHO JUNIOR, Elmir Duclerc. Ensaio para uma teoria agnóstica do processo penal. Revista Eletrônica Direito e Política, Programa de Pós-Graduação Stricto Sensu em Ciência Jurídica da UNIVALI, Itajaí, v.10, n.2, $1^{0}$ quadrimestre de 2015. Disponível em: www.univali.br/direitoepolitica - ISSN 1980-7791.

Outrossim, seria possível distinguir várias concepções de ciência, conforme essa garantia de validade esteja fundada na demonstração, descrição ou corrigibilidade ${ }^{8}$.

É preciso lembrar, também aqui, que estamos pisando num terreno um tanto movediço. É que o fim de algumas certezas, provocado por descobertas mais recentes da própria ciência (o inconsciente de Freud, os quanta de Einstein, por exemplo) acabaram conduzindo o conhecimento científico a alguns becos sem saída, obrigando-o a dialogar, de novo, com o senso comum. É o que explica que, conforme alguns autores contemporâneos, a oposição (e a superioridade) em relação ao senso comum apareça mitigada, e a ciência seja apresentada como "a hipertrofia das capacidades que todos têm". Pondera-se, entretanto, que "isso pode ser bom, mas pode ser muito perigoso. Quanto maior a visão em profundidade, menor a visão em extensão. A tendência da especialização é conhecer cada vez mais de cada vez menos" ${ }^{\prime 9}$.

No que se refere à técnica, é preciso ter em mente que o sentido geral desse termo parece coincidir com o sentido geral de arte, alcançando todo conjunto de regras aptas a dirigir eficazmente uma atividade qualquer. Já a partir de Kant, entretanto, fala-se de técnica como algo vinculado à natureza e à causalidade (necessária), insuscetível, portanto, de ser aplicada no âmbito da filosofia (da filosofia prática, sobretudo). Observe-se, ademais, que o termo acabou sendo entendido também como um procedimento qualquer (não necessariamente

\footnotetext{
${ }^{8}$ ABBAGNANO, Nicola, Dicionário de filosofia, p. 442-456. A primeira vertente teria suas origens ainda em Platão, que comparava a opinião às estátuas de Dédalo, sempre em atitude de fuga, exigindo serem "atadas" com um raciocínio causal. Essa noção de demonstração como característica fundamental da ciência estende-se para além da Antiguidade, com Euclides, atravessa a Idade Média e projeta-se até mesmo na modernidade (Descartes, Spinoza, e mesmo Kant), ainda que divida espaço, também, com a noção de "experiência sensata" de Galileu. A concepção descritiva da ciência começa a se constituir com Bacon, Newton e os filósofos iluministas. Seu fundamento é a distinção baconiana entre antecipação e interpretação da natureza: a interpretação consiste em "conduzir os homens diante dos fatos particulares e das suas ordens". Embora suas origens sejam francamente iluministas, será amplamente recepcionada também no positivismo oitocentista (Comte). Por fim, tem-se a concepção que reconhece como garantia única da validade da ciência a sua autocorrigibilidade. Trata-se, conforme o mestre italiano, de uma concepção das vanguardas mais críticas ou menos dogmáticas da metodologia contemporânea e ainda não alcançou o desenvolvimento das outras duas concepções acima. O seu pressuposto básico é o falibilismo de todo conhecimento humano (Pierce e, sobretudo, Popper).
}

${ }^{9}$ ALVES, Rubem Azevedo. Filosofia da ciência: introdução ao jogo e suas regras. São Paulo: Ars Poética, 1996, p. 10. 
RAMALHO JUNIOR, Elmir Duclerc. Ensaio para uma teoria agnóstica do processo penal. Revista Eletrônica Direito e Política, Programa de Pós-Graduação Stricto Sensu em Ciência Jurídica da UNIVALI, Itajaí, v.10, n.2, $1^{\circ}$ quadrimestre de 2015. Disponível em: www.univali.br/direitoepolitica - ISSN 1980-7791.

vinculado à causalidade), desde que regido por normas e provido de certa eficácia.

O que mais nos interessa, contudo, é o sentido racional da técnica, como algo que acompanha a vida do homem sobre a Terra, uma verdadeira estratégia de sobrevivência e bem-estar, que alcança seu ápice, sem dúvida, no positivismo do século XIX.

Na passagem do século XIX para o século XX, todavia, a técnica já se apresenta como um problema, por conta das dramáticas consequências humanas produzidas por sua consagração irrestrita no mundo moderno. Esse clima de desconfiança em relação à técnica, aliás, atravessa e se intensifica mesmo com o final do ciclo das duas grandes guerras, chegando a pôr em questão a própria razão, ou, pelo menos, a associação entre ciência e técnica como manifestação de uma razão inautêntica, escravizada a objetivos utilitários e distanciada de sua verdadeira função: o conhecimento desinteressado do ser, a contemplação. No fundo, põe-se em debate a própria sociedade contemporânea, que estaria fundada na técnica e dominada pela tecnocracia ${ }^{10}$.

A partir dos pressupostos acima delineados, podemos já dizer que uma teoria do processo penal, no momento atual do desenvolvimento da trajetória histórica do saber jurídico, deve, sem dúvida alguma, buscar na filosofia uma instância crítica (que lhe dê embasamento e, ao mesmo tempo, capacidade de renovação permanente), voltando-se para o seu objeto último de estudo (o processo penal), a fim de compreendê-lo transdisciplinarmente (a partir de vários "olhares") e, ao mesmo tempo, fornecer um instrumental técnico capaz de municiar os atores do sistema de justiça criminal na sua lida diária.

${ }^{10}$ ABBAGNANO, Nicola, Dicionário de filosofia, p. 442-456. 
RAMALHO JUNIOR, Elmir Duclerc. Ensaio para uma teoria agnóstica do processo penal. Revista Eletrônica Direito e Política, Programa de Pós-Graduação Stricto Sensu em Ciência Jurídica da UNIVALI, Itajaí, v.10, n.2, $1^{\circ}$ quadrimestre de 2015. Disponível em: www.univali.br/direitoepolitica - ISSN 1980-7791.

\section{PRESSUPOSTOS filosóficos PARA UMA TEORIA DO PROCESSO PENAL (OU: POR QUE UMA TEORIA AGNÓSTICA)}

Como dito acima, a primeira tarefa de uma teoria científica deve estar voltada à identificação de seus pressupostos filosófico-críticos mais profundos.

No caso presente, desde já anunciamos a nossa fidelidade a uma forma específica de compreensão do fenômeno criminal fundada na ideia de agnosticidade da pena, na contramão, portanto, de toda uma tradição construída em torno da aspiração de dar-Ihe justificação racional.

Da leitura da obra de Ferrajoli ${ }^{11}$ (que tomamos como exemplo da mais refinada tentativa recente de fazê-lo), o que se percebe é que a própria concepção do seu modelo garantista decorre necessariamente de seu posicionamento frente ao problema da justificação da pena e do processo, ou seja, das respostas que encontra para as questões do se e do por que punir.

Inicialmente, observa-se que o problema é visto pelo mestre como uma questão de cálculo comparativo entre os benefícios e malefícios da punição ou da ausência de punição para os comportamentos ditos desviados, e reclama ser enfrentado a partir da separação ilustrada entre direito, moral e natureza, própria do pensamento liberal do século XVIII (muito embora todo o movimento ideológico em sentido contrário, verificado principalmente a partir da segunda metade do século XIX). Daí decorre, portanto, a crítica ética das diversas doutrinas de justificação da pena, bem como das próprias tendências abolicionistas, já que a resposta sobre o se (se seria justificável a violência estatal da pena) admite, do ponto de vista lógico, uma resposta negativa.

As principais tendências abolicionistas contemporâneas acabam por desembocar em concepções de sociedades antitéticas, mas igualmente deletérias: de um lado, a sociedade selvagem do bellum omnium contra omnes e, de outro, a insuportável sociedade disciplinar ou panóptica denunciada por Foucault ${ }^{12}$. No

\footnotetext{
${ }^{11}$ FERRAJOLI, Luigi, Derecho y razón: teoría del garantismo penal. 3. ed. Madrid: Trotta, 1998.

12 FOUCAULT, Michel, Vigiar e punir: nascimento da prisão. 19. ed. Tradução de Raquel Ramalhete. Petrópolis: Vozes, 1999, p. 162-187.
} 
RAMALHO JUNIOR, Elmir Duclerc. Ensaio para uma teoria agnóstica do processo penal. Revista Eletrônica Direito e Política, Programa de Pós-Graduação Stricto Sensu em Ciência Jurídica da UNIVALI, Itajaí, v.10, n.2, $1^{\circ}$ quadrimestre de 2015. Disponível em: www.univali.br/direitoepolitica - ISSN 1980-7791.

entanto, haveria em tais doutrinas, um mérito indiscutível: fazer surgir a reflexão sobre a necessidade de justificação ético-política da pena e do processo, posto que, sem elas, não se concebe a questão do se, já referida.

As doutrinas justificacionistas, por sua vez, seriam classificadas em dois grandes grupos: as de cunho retribucionista e as de cunho utilitarista.

As primeiras, como é intuitivo, à semelhança dos antigos sistemas mágicos e religiosos de solução de conflitos (a expiação que faz desaparecer o pecado), concebem a pena como um fim em si mesmo (o mal praticado pelo indivíduo reclamaria uma retribuição na forma de uma punição) e supõem a existência de uma lógica (não demonstrável) entre crime e castigo, dando ensejo, nesse passo, à sustentação ideológica de sistemas radicalmente autoritários e ilimitados de direito e processo penal, visto que, para eliminar o mal, pode-se ir ao extremo de eliminar o responsável por ele.

As doutrinas utilitaristas, por sua vez, estão todas unidas por um traço comum: "la concepción de la pena como medio, más que como fin o valor"13. O problema, todavia, é que, partindo-se da ideia clássica de utilitarismo como a maior felicidade possível, compartilhada pelo maior número possível de pessoas, as doutrinas utilitaristas da pena e do processo acabam levando em conta apenas a felicidade na forma de maior segurança possível para a maioria composta pelos não desviados, em detrimento do "mínimo sufrimiento necesario que haya que infligir a la minoria formada por los desviados ${ }^{14}$.

Sob essa ótica, portanto, a utilidade da pena seria basicamente a de prevenir novos crimes, e esse é o traço comum que une as conhecidas doutrinas da prevenção geral (positiva ou negativa) e da prevenção especial (positiva ou negativa) que, como se verá, não asseguram absolutamente o pretendido equilíbrio na conta de custos e benefícios da manutenção do sistema, mas, antes, têm servido de fundamento para sistemas de direito e processo penal autoritários.

${ }^{13}$ FERRAJOLI, Luigi, Derecho y razón: teoría del garantismo penal, p. 258.

${ }^{14}$ FERRAJOLI, Luigi, Derecho y razón: teoría del garantismo penal, p. 261. 
RAMALHO JUNIOR, Elmir Duclerc. Ensaio para uma teoria agnóstica do processo penal. Revista Eletrônica Direito e Política, Programa de Pós-Graduação Stricto Sensu em Ciência Jurídica da UNIVALI, Itajaí, v.10, n.2, $1^{\circ}$ quadrimestre de 2015. Disponível em: www.univali.br/direitoepolitica - ISSN 1980-7791.

Para Ferrajoli, entretanto, todas essas teorias seriam falhas ${ }^{15}$, fazendo-se necessário, portanto, uma verdadeira mudança de foco no que se refere ao próprio conceito de utilitarismo, entendido, neste passo, como máxima segurança para a maioria não desviada, mas sem abrir mão de um mínimo sofrimento necessário para a minoria desviada. Assim, o que justifica a pena, em última análise, é a sua função dissuasória, associada à necessidade de evitar vinganças desproporcionais ao criminoso.

Através dessa via, note-se bem, preservar-se-ia a distinção ilustrada entre moral, direito e natureza, evitar-se-ia a objeção moral kantiana de que nenhum homem pode ser instrumento da felicidade de outrem e equilibrar-se-ia, ainda, a relação custo/benefício da intervenção penal, pela imposição de certos limites ao poder punitivo, através de um sistema de garantias penais e processuais penais.

15 FERRAJOLI, Luigi, Derecho y razón: teoría del garantismo penal, p. 259-280. A prevenção especial negativa pretende eliminar o crime pela neutralização do criminoso, no que acaba confundindo direito com natureza; repousa, ademais, no pressuposto indemonstrável de que a prática de um, dois ou dez delitos passados indica que outros virão pela frente, e acaba por legitimar, também, sistemas autoritários e ilimitados: a sociedade, ameaçada pelo homem naturalmente degenerado, tem razões suficientes para, inclusive, amputar o membro defeituoso. A doutrina da prevenção especial positiva pretende eliminar o crime pela reeducação do criminoso e acaba por confundir direito e moral, com sérios riscos para a liberdade de consciência, pois aquilo que é moral para uns pode ser imoral para outros; outrossim, tendo em vista a distinção entre elementos recuperáveis e irrecuperáveis, abre-se caminho para a construção de sistemas ilimitados: aos irrecuperáveis, só resta serem eliminados. A prevenção geral positiva, para Ferrajoli, confunde direito com moral (crimes como ações que implicam sempre atentados contra a moral social) e favorecem também o surgimento de sistemas penais autoritários, posto que, se o objetivo é reforçar a confiança no Estado, pode-se até mesmo punir o inocente. Por fim, a prevenção geral negativa, embora seja a única tendência que não confunde direito, moral e natureza, enfrenta também sérias objeções: primeiro, se a pena se presta a desestimular novos crimes, com a punição exemplar, não é exigível que o acusado seja necessariamente culpado; depois, permanece em aberto o problema do conteúdo material dessas ações que se pretende desestimular, ou seja, pode-se pretender desestimular comportamentos morais, ou até mesmo determinadas características essenciais da pessoa, abrindo espaço, assim, para um direito penal de autor e não de ato; veja-se, ainda, que como bem registra Ferrajoli, se a função dissuasória nunca se cumpre integralmente, posto que sempre haverá comportamentos desviantes do padrão normativo, a consequência inevitável é o aumento progressivo das sanções, numa tendência , que, segundo Betiol, citado pelo mestre, teria como trágico ponto de chegada a pena de morte para todos os delitos; finalmente, note-se que as doutrinas da prevenção geral negativa, como, de resto , todas as concepções utilitaristas tradicionais, não conseguem oferecer resposta à chamada objeção moral kantiana, segundo a qual, num universo dominado pelo utilitarismo, o homem, pelo menos a pessoa humana, goza do status de fim em si mesmo, e, como tal, não pode ser usado como meio para a felicidade de outros homens. 
RAMALHO JUNIOR, Elmir Duclerc. Ensaio para uma teoria agnóstica do processo penal. Revista Eletrônica Direito e Política, Programa de Pós-Graduação Stricto Sensu em Ciência Jurídica da UNIVALI, Itajaí, v.10, n.2, $1^{\circ}$ quadrimestre de 2015. Disponível em: www.univali.br/direitoepolitica - ISSN 1980-7791.

Zaffaroni ${ }^{16}$, por seu turno, começa por perguntar-se o que se pode mesmo chamar de direito penal, e o que se pode chamar propriamente de pena.

Nesse passo, partindo da premissa de que a pena criminal constitui uma das formas através das quais a sociedade (como regra, mor meio do Estado) intervém nos conflitos, sempre conforme alguns modelos conhecidos, historicamente, e com características bem específicas, temos: a) o modelo reparador; b) o modelo conciliador; c) o modelo corretivo; d) o modelo terapêutico; d) o modelo punitivo.

O confronto do modelo punitivo com os outros, ademais, deixa a descoberto a sua pouca aptidão para de fato solucionar os conflitos, senão simplesmente suspendê-los, isto é, proporcionar-lhes uma resolução meramente simbólica, que exclui a vítima e acaba delegando ao tempo a função real de dissipá-lo. Além disso (e ao contrário do que ocorre com os demais), dificilmente pode ser combinado com outros modelos para tomar por empréstimo suas potencialidades pacificadoras.

Por outro lado, partindo da premissa de que o todo poder do Estado, numa perspectiva republicana, precisa estar (discursivamente) fundamentado em alguma utilidade, é fácil perceber que as normas e instituições estatais podem desempenhar funções manifestas, latentes e eventuais. A descoberta dessas três categorias permite surpreender o irrecusável conteúdo político do direito penal, e sua identificação, mais ou menos intensa, com modelos autoritários ou democráticos de Estado, vale dizer, com o modelo do Estado de polícia ou do Estado de direito. Por outro lado, permite também chegar a uma compreensão mais abrangente sobre o que é de fato uma lei penal, na medida em que propicia um verdadeiro desvelamento da natureza punitiva de leis, que não assumem declaradamente essa função. A própria pena, como manifestação de um determinado modelo de intervenção estatal para a solução de conflitos, passa a ser vista com olhos críticos e, por assim dizer, agnósticos, que a par de identificarem as suas funções latentes, nem por isso the conferem qualquer

16 ZAFFARONI, Eugenio Raúl et al. Direito penal brasileiro: teoria geral do direito penal. Tradução de Nilo Batista; Helena Ferreira. Rio de Janeiro: Revan, 2003, p. 38 e seguintes. 
RAMALHO JUNIOR, Elmir Duclerc. Ensaio para uma teoria agnóstica do processo penal. Revista Eletrônica Direito e Política, Programa de Pós-Graduação Stricto Sensu em Ciência Jurídica da UNIVALI, Itajaí, v.10, n.2, $1^{\circ}$ quadrimestre de 2015. Disponível em: www.univali.br/direitoepolitica - ISSN 1980-7791.

legitimação a priori. Trata-se, pois, de reconhecer a existência não de um jus puniendi que precisa ser legitimado, mas de uma potentia puniendi que precisa ser contida.

Criam-se as condições para um conceito de pena obtido negativamente, isto é, que atribui esse caráter a toda e qualquer medida estatal de coerção que não tenha o caráter reparador (ou restitutivo ${ }^{17}$ ) e tampouco o caráter de coerção $\operatorname{direta}^{18}$. Tem-se, portanto, que a pena é "uma coerção, que impõe uma privação de direitos ou uma dor, mas não repara nem restitui, nem tampouco detém as lesões em curso ou neutraliza perigos iminentes" ${ }^{19}$.

Ao fim e ao cabo, a pena criminal resta tão legitimada quanto a guerra e, nesse sentido, talvez represente o maior dos paradoxos do próprio fenômeno jurídico da atualidade.

Uma teoria agnóstica do processo penal, portanto, é aquela que não pretende ignorar ou ocultar ideologicamente esse paradoxo, mas, antes, reconhecê-lo na sua irracionalidade, mas procura dar-Ihe um tratamento minimamente racional, conforme uma lógica de redução de danos.

O diálogo com o pensamento criminológico crítico, por outro lado, deixa evidenciado que, como fenômeno sócio-político, a punição, tal como a guerra, sempre existiu, muito antes do surgimento do fenômeno jurídico, e ainda hoje atua para além do Direito, na forma de sistemas penais paralelos ou subterrâneos (milícias e grupos de extermínio, por exemplo), e talvez tenha suas

\footnotetext{
17 ZAFFARONI, Eugenio Raúl et al, Direito penal brasileiro: teoria geral do direito penal, p. 87 e seguintes. O modelo reparador, prevalecente no direito privado, não deixa de ter, evidentemente, um componente utópico diretamente ligado aos níveis de inefetividade (marcadamente nos países periféricos), mas, como ponderam os autores estudados, seria sempre uma utopia a ser perseguida, na medida que descortina um horizonte de efetiva melhoria da vida em sociedade, muito ao contrário do que ocorre com a utopia negativa, de integral cumprimento da programação criminalizante primária, que tornaria a vida social insuportável.

${ }^{18}$ ZAFFARONI, Eugenio Raúl et al, Direito penal brasileiro: teoria geral do direito penal, p. 102. Como esclarecem Raúl Eugenio Zaffaroni e outros: "Toda administração demanda um poder coercivo que lhe permita executar suas decisões. Tal poder é exercido de diversas maneiras. As mais comuns são as que se fazem através de: a) execução subsidiária do ato omitido pelo particular (efetiva-se sobre o seu patrimônio); b) multas coercivas; c) coerção direta". Essa última forma seria a que mais se aproxima (e mais facilmente se confunde) com a pena, sobretudo na perspectiva de suas funções declaradas e latentes.
}

${ }^{19}$ ZAFFARONI, Eugenio Raúl et al, Direito penal brasileiro: teoria geral do direito penal, p. 99. 
RAMALHO JUNIOR, Elmir Duclerc. Ensaio para uma teoria agnóstica do processo penal. Revista Eletrônica Direito e Política, Programa de Pós-Graduação Stricto Sensu em Ciência Jurídica da UNIVALI, Itajaí, v.10, n.2, $1^{\circ}$ quadrimestre de 2015. Disponível em: www.univali.br/direitoepolitica - ISSN 1980-7791.

raízes mais profundas em irrecusáveis condicionantes antropológicas, relacionadas à luta dos nossos ancestrais por sexo e comida, tal como ainda vemos entre grupos sociais de animais e, especialmente, entre os primatas geneticamente mais próximos do homo sapiens sapiens.

A pena, portanto, não pode ser justificada racionalmente, mas explicada antropologicamente, como resquício de um processo evolutivo que acabou condicionando a humanidade racional a pensar a vida social em termos de mérito e vingança.

Esses são, sem dúvida alguma, os vetores que determinam a compreensão básica da humanidade sobre o fenômeno da punição estatal. Diante da notícia de um delito horrendo, absolutamente ninguém, do mais ignorante ao mais culto dos juristas, escapa de pensar na punição como algo merecido pelo seu autor. $\mathrm{E}$ isso é assim em todo o ocidente, em que pese toda a tradição da filosofia cristã, que dividiu a história da humanidade justamente pela novidade mítica de sua mensagem de perdão e compreensão, que encontraria, na modernidade, uma série de confirmações científicas, desde a psicologia profunda, a sociologia e, mais recentemente, a neurociência, todas elas a nos dizer, cada uma a seu modo, que somos basicamente determinados por fatores de toda ordem que não escolhemos, a partir, inclusive, da própria escolha por vir ou não a esse mundo.

Se existe, portanto, alguma racionalidade na pena criminal, ela deve ser entendida como uma espécie de capitulação da razão à nossa animalidade ancestral. Em suma, trata-se de uma racionalidade que reconhece os seus próprios limites, e não pode fazer muito mais que reconhecer a vingança como um elemento essencial da formação da própria psique humana, que extrapola a consciência/inconsciência individual e se projeta sobre o coletivo.

Assim se explica, segundo pensamos (mas não só por isso), o paradoxo proposto por Zaffaroni entre um Estado de Direito que tem que conviver, permanentemente, com o Estado de Polícia ${ }^{20}$, como duas faces de uma mesma

${ }^{20}$ ZAFFARONI, Eugenio Raúl et al, Direito penal brasileiro: teoria geral do direito penal, p. 89 e seguintes. 
RAMALHO JUNIOR, Elmir Duclerc. Ensaio para uma teoria agnóstica do processo penal. Revista Eletrônica Direito e Política, Programa de Pós-Graduação Stricto Sensu em Ciência Jurídica da UNIVALI, Itajaí, v.10, n.2, $1^{\circ}$ quadrimestre de 2015. Disponível em: www.univali.br/direitoepolitica - ISSN 1980-7791.

moeda. Em outras palavras, reconhecer a pena como fenômeno, sem conferir-lhe justificação racional, seria algo como "dar a Cesar o que é de Cesar". Nem um centavo a mais.

\section{DOS PRESSUPOSTOS CIENTÍfICOS DE UMA TEORIA AGNÓSTICA DO PROCESSO PENAL (OU: POR QUE UMA TEORIA DO PROCESSO PENAL)}

Partindo do que já deixamos assentado acima, sobre a tarefa e os limites do conhecimento científico, temos que uma boa teoria científica é aquela capaz de apresentar a melhor explicação possível (ainda que em caráter sempre contingente e provisório) para os objetos ou fenômenos que pretende estudar, e com o maior grau possível de redução de complexidade.

Assim, parece claro que, à medida em que se postula a construção de uma teoria do processo penal, a um só tempo afirmamos que existe algo essencialmente diferente entre o processo penal e o processo não penal enquanto fenômenos, e que já não é mais possível trabalhar com a ilusão de uma teoria geral do processo.

Que os objetos são distintos, isso parece que ninguém mais pode duvidar. Como vimos, aliás, esses dois instrumentos correspondem, historicamente, a dois métodos estatais de resolução de conflitos que são diametralmente opostos: o modelo reparador e o modelo punitivo.

Entretanto, resta sempre a dúvida sobre se isso seria o bastante para sustentar um descolamento total e assinar o atestado de óbito da chamada teoria geral do processo, que, no fim das contas, seria ainda útil e necessária, para qualquer ideal de redução de complexidade, tão caro à ciência em geral. Afinal, por que não aproveitar todo um conjunto de conceitos como ação, jurisdição e processo, sanção, nulidade, partes etc., que foram criados no âmbito de um direito processual privatístico, apenas adaptando-o ao processo penal?

Para oferecer resposta a essa questão, será necessário voltar os olhos para a história. 
RAMALHO JUNIOR, Elmir Duclerc. Ensaio para uma teoria agnóstica do processo penal. Revista Eletrônica Direito e Política, Programa de Pós-Graduação Stricto Sensu em Ciência Jurídica da UNIVALI, Itajaí, v.10, n.2, $1^{\circ}$ quadrimestre de 2015. Disponível em: www.univali.br/direitoepolitica - ISSN 1980-7791.

Para quem bem compreende a história do direito penal moderno, à luz do que acabamos de examinar, não é difícil perceber uma relação de complementaridade entre a teoria do delito, de um lado, e a teoria geral do processo, do outro (ambas são produto da modernidade) que não tem a ver apenas com a velha dicotomia (artificial e questionável) entre direito substantivo e direito adjetivo. Por trás dessa dicotomia artificial e forçada, na verdade, o que temos é a construção, desde a segunda metade do século XIX, até as primeiras décadas do século $\mathrm{XX}$, de uma tecnologia surgida originariamente no âmbito do direito privado, que terminou sendo simplesmente acoplada ao direito penal (e à pré-existente teoria do delito), dando ensejo, assim, ao surgimento de um direito processual-penal como aplicação específica de um direito processual tecnicista.

Vejamos, pois.

Os antecedentes mais remotos da teoria do delito (como teoria do tipo) aparecem ainda no renascimento, com Tiberius Decianus, mas suas primeiras formulações com pretensões modernamente científicas surgirão, mesmo, com a construção do sistema Liszt-Beling, na passagem do século XIX para o séc. $X X^{21}$.

Conforme Niceto Alcalá-Zamora y Castilho ${ }^{22}$, a história do pensamento jurídico processual, no ocidente, pode ser estudada esquematicamente em quatro fases, a partir de um período primitivo (que alcança, para trás, até o século XI da era cristã), passando pela Escola Justicialista de Bolonha, pelo procedimentalismo francês e culminando com o processualismo dito científico,que "nasce" alemão, com Bülow, e depois se "naturaliza" italiano, com Chiovenda.

Algum tempo depois, o direito processual chega às Américas - já com o rótulo de científico, trazido por inúmeros professores espanhóis que foram obrigados a

\footnotetext{
${ }^{21}$ Nesse sentido, TAVARES, Juarez. Teorias do delito: variações e tendências. São Paulo: Revista dos Tribunais, 1980, p. 11-16. ZAFFARONI, Eugenio Raúl et al, Direito penal brasileiro: teoria geral do direito penal, p.582-583. Para Zaffaroni e outros, o penalismo de Liszt, em fins de século XIX, pode ser considerado um positivismo com tendência ao pensamento, na medida em que concebe (com absoluta originalidade) a dogmática penal como tendo uma função limitadora do poder punitivo, que precisa ser resgatada. Nas suas palavras, a dogmática penal seria, pois, como a Carta Magna do delinquente.
}

22 ALCALÁ-ZAMORA Y CASTILLO, Niceto. Estudios de Teoría General e Historia del Proceso. México: Universidad Nacional Autónoma de México, 1992, p. 295. 
RAMALHO JUNIOR, Elmir Duclerc. Ensaio para uma teoria agnóstica do processo penal. Revista Eletrônica Direito e Política, Programa de Pós-Graduação Stricto Sensu em Ciência Jurídica da UNIVALI, Itajaí, v.10, n.2, 10 quadrimestre de 2015. Disponível em: www.univali.br/direitoepolitica - ISSN 1980-7791.

deixar seu país durante a Guerra Civil, e que eram fortemente influenciados pelo processualismo alemão. Cumpre registrar, entretanto, ${ }^{23}$ a influência do processualismo italiano no Brasil, pelas mãos de Enrico Tullio Liebman, que, como se sabe, aqui ensinou durante muitos anos, na Universidade de São Paulo, e foi responsável pela formação de muitos dos nossos processualistas, como a própria professora Ada Pellegrini Grinover ${ }^{24}$.

O problema, note-se bem, é que a difusão de um processualismo científico, (estruturado, fundamentalmente, sobre os conceitos de ação e processo), acaba inspirando o surgimento de uma teoria geral do processo da qual o processo penal seria apenas uma subespécie. O resultado é que, sob o argumento da racionalização e da compreensão sistemática do ordenamento jurídico, o que se obteve foi uma contaminação do processo penal com a própria lógica do processo civil, de cunho individualista e utilitarista, totalmente incompatível, portanto, com a gravidade das questões em torno da liberdade humana e da punição. ${ }^{25}$

Parece claro, portanto, que a captura do processo penal por uma técnica criada para otimizar o processo decisório de processos não penais, e preponderantemente patrimoniais, acaba sendo mais um passo na direção da tecnicização dos mecanismos de resolução de conflitos penais, em total harmonia, portanto, com o discurso criminológico do século XIX, sob forte influência da ciência positivista.

${ }^{23}$ ALCALÁ-ZAMORA y CASTILLO, Estudios de Teoría General e Historia del Proceso, p. 320325.

${ }^{24}$ SILVA, Ovidio Araújo Baptista da. Processo e ideologia: o paradigma racionalista. 2. ed. Rio de Janeiro: Forense, 2006, p. 37. O nosso processualismo, portanto, nasce com a marca do dogmatismo e do cientificismo, o que explica, de certa forma, que "Na literatura brasileira, o prestígio das obras institucionais de processo civil é diretamente proporcional ao estilo abstrato, more geométrico, utilizado por seus autores".

${ }^{25}$ COUTINHO, Jacinto Nelson de Miranda. A Lide e o Conteúdo do Processo Penal. Curitiba: Juruá, 1989, p. 118-119. Nesse sentido, também, a crítica de Jacinto Nelson Miranda Coutinho, para quem "teoria geral do processo é engodo, teoria geral do processo é a do processo civil e, a partir dela, as demais". CARVALHO, Salo. Antimanual de Criminologia. Rio de Janeiro: Lúmen Juris, 2008, p. 27. Também Salo de Carvalho, ao denunciar que "A pretensão científica totalizadora da teoria geral do processo capacita seu conteúdo desde o processo civil, inferiorizando as diversidades das esferas processuais". 
RAMALHO JUNIOR, Elmir Duclerc. Ensaio para uma teoria agnóstica do processo penal. Revista Eletrônica Direito e Política, Programa de Pós-Graduação Stricto Sensu em Ciência Jurídica da UNIVALI, Itajaí, v.10, n.2, $1^{\circ}$ quadrimestre de 2015. Disponível em: www.univali.br/direitoepolitica - ISSN 1980-7791.

O mais grave, contudo, é que uma redução nesses termos (o processo penal como um sub-ramo da teria geral do processo) significa, sem dúvida, abdicar de compreender uma parte vital do direito penal (num sentido mais abrangente) criticamente, ou seja, de percebê-lo como um instrumento desenvolvido pelas sociedades supostamente civilizadas para, muito mais que restituir as coisas ao seu status quo ante, legitimar a imposição de um sofrimento adicional a pessoas que praticam certos e determinados atos, com a finalidade de controlar politicamente o seu comportamento. Desse modo, acabam eclipsados aqueles princípios construídos ainda no século XVIII, alçados à condição de Direitos Humanos por inúmeros documentos internacionais, e consagrados como direitos fundamentais do indivíduo em todas as constituições democráticas ocidentais contemporâneas.

Enfim, o envolvimento do direito penal com a técnica processual parece militar muito claramente para cegar os juristas, entretendo-os com as ferramentas da técnica e impedindo-os de perceber, como ensina Alberto Binder, que por trás de conceitos como ação e processo, por exemplo, "[...] está o cárcere, e o cárcere é uma jaula para prender humanos" 26 .

A história demonstra, afinal, que não existe - especialmente em áreas do saber como o Direito, algo como o conceito puro, descontaminado de cargas ideológicas de toda ordem, nem mesmo das mais ingênuas pretensões da filosofia analítica.

\section{TEORIA agnóstica do processo penal e técnica: algumas QUESTÕES RELACIONADAS AO REGIME DE AÇÃO, JURISDIÇÃO E PROCESSO}

No limite entre ciência e técnica, já dissemos, uma boa teoria deve fornecer elementos e categorias conceituais adequados para que os atores do sistema de justiça possam desempenhar bem a sua tarefa.

${ }^{26}$ BINDER, Alberto. Introdução ao Direito Processual Penal. Rio de Janeiro: Lumen Juris, 2000, p. XXI. 
RAMALHO JUNIOR, Elmir Duclerc. Ensaio para uma teoria agnóstica do processo penal. Revista Eletrônica Direito e Política, Programa de Pós-Graduação Stricto Sensu em Ciência Jurídica da UNIVALI, Itajaí, v.10, n.2, $1^{\circ}$ quadrimestre de 2015. Disponível em: www.univali.br/direitoepolitica - ISSN 1980-7791.

Assim, optamos por enumerar algumas questões que se colocam à reflexão desde o primeiro momento, relacionadas ao regime de ação penal e à correlata atuação das partes no processo, à jurisdição, e ao próprio tema do processo, esse tripé fundamental que herdamos acriticamente da Teoria Geral do Processo Civil.

Vejamos, pois.

\subsection{Teoria agnóstica e ação}

Assim, a ação seria um direito subjetivo (faculdade) público, autônomo e abstrato de invocar a jurisdição (poder) mediante o processo (instrumento).

Aqui, as consequências do "acoplamento" tecnológico entre Teoria do Delito e Teoria do Processo Civil se fazem sentir de maneira devastadora, dando ensejo a uma série de perplexidades que vão sendo ao longo dos anos (dos séculos, já) como que varridas para debaixo de um tapete dogmático, e reproduzidas acriticamente em cursos e manuais de consumo rápido.

Como conceber, por exemplo, a noção de faculdade com a ideia de obrigatoriedade da ação penal? Uma faculdade do Estado não seria sempre a expressão de um poder e não propriamente de um direito? Como compatibilizar a autonomia do direito de ação em relação ao direito material (de punir), se a sanção penal só pode ser aplicada no ambiente do processo? E como se explica que o Ministério Público possa (e deva) deixar de processar alguém (pedindo arquivamento) por questões de mérito (art. 397, do CPP)? E é possível mesmo falar de um direito estatal de punir? Não seria mais adequado, também aqui, falar de um poder?

As dificuldades só se aprofundam, na medida em que nos debruçamos sobre as chamadas condições da ação a partir do mesmo esquema herdado do processo civil. 
RAMALHO JUNIOR, Elmir Duclerc. Ensaio para uma teoria agnóstica do processo penal. Revista Eletrônica Direito e Política, Programa de Pós-Graduação Stricto Sensu em Ciência Jurídica da UNIVALI, Itajaí, v.10, n.2, $1^{\circ}$ quadrimestre de 2015. Disponível em: www.univali.br/direitoepolitica - ISSN 1980-7791.

Por exemplo, já se discutiu muito (pelo menos num nível superficialmente dogmático) se faz sentido discutir a questão do interesse de agir em processo penal, já que a vantagem prática a ser obtida com o provimento judicial já estaria estabelecida a priori com a previsão abstrata de apenação (mínima e máxima) para todas as condutas típicas. Pelas mesmas razões, discute-se se é possível falar de possibilidade jurídica do pedido, já que no processo penal este pedido já viria necessariamente dado pela simples previsão legal do delito, com a sua respectiva apenação.

\subsection{Teoria agnóstica e processo}

No que se refere ao processo, talvez a pior herança da qual precisamos nos livrar seja a própria ideia de processo como relação jurídica, que se aperfeiçoa com a citação válida e avança no tempo com uma série atos que tendem à composição final do litígio, conforme o direito.

Quem experimentou a atuação do poder punitivo na própria carne sabe que ela tem início no curso do próprio processo. Isso já tinha sido percebido por pelo próprio Carnelutti, mas no Brasil do início de século XXI se apresenta de uma forma acachapante, dadas as condições carcerárias e o grande percentual de presos provisórios já por todos conhecido.

Some-se a isso que a atuação mais violenta do poder punitivo, na esmagadora maioria dos casos, acontece durante o inquérito policial. É ali, na escuridão das celas das delegacias, na exposição não autorizada na mídia, na sonegação de direitos e garantias, que já começa a violência da vingança. E é ali, no ambiente inquisitorial, que a sorte do acusado é traçada, uma vez que as instruções processuais são, basicamente, a reprodução acrítica daquilo que já foi "esclarecido" na delegacia de polícia.

Em suma, falamos de processo (com contraditório, ampla defesa, juiz imparcial) como garantia, como dique de segurança que deveria separar o acusado da punição, mas na prática ele tem servido apenas como forma de punição 
RAMALHO JUNIOR, Elmir Duclerc. Ensaio para uma teoria agnóstica do processo penal. Revista Eletrônica Direito e Política, Programa de Pós-Graduação Stricto Sensu em Ciência Jurídica da UNIVALI, Itajaí, v.10, n.2, $1^{\circ}$ quadrimestre de 2015. Disponível em: www.univali.br/direitoepolitica - ISSN 1980-7791.

antecipada, e como disfarce de legitimidade a uma violência que acontece muito antes, longe dos olhos do Ministério Público, do judiciário, e, o que é pior, da defesa técnica.

Talvez, aqui, seja necessário resgatar, para o processo penal, a noção goldschmidtiana, de situação jurídica ${ }^{27}$ (tão ao gosto do homenageado!), que independe, inclusive, de uma acusação formalmente apresentada, bastando, para que se configure, que alguém esteja potencial e plausivelmente exposto à atuação do sistema de punição. Também aqui, a noção clássica (não penal) de processo serviria para tão pouca coisa que somente por amor à tradição preservaríamos o seu nomen juris.

\subsection{Teoria agnóstica e jurisdição}

No âmbito da jurisdição, talvez o problema mais importante gire em torno do dogma da unidade, isto é, daquela ideia de que, seja qual for o âmbito de atuação - penal ou não-penal, o que opera é o poder do Estado de dirimir conflitos, de atuar ou não nas pretensões, aplicando ou negando a aplicação do direito objetivo, em caráter definitivo, e agindo de forma substitutiva, definitiva e imparcial.

Como sabemos, é isso que tem inspirado a preservação de áreas de influência recíproca entre as decisões penais e não penais, tal como ocorre no âmbito da ação civil ex delicti (nos termos dos arts. 63, caput, e 64 do CPP; 91, I, do CP; 935 do CC; e 265, § 50, do CPC), de um lado; e, do outro, na esfera das chamadas questões prejudiciais heterogêneas, absolutas ou relativas (nos termos dos arts. 92 a 94 do CPP); tudo isso sob o argumento de evitar decisões contraditórias.

É preciso ter em mente, contudo, que mesmo no âmbito da jurisdição penal a aspiração de não contradição entre as decisões não é absoluta, mas cede em

27 GOLDSCHIMIDT, James. Teoría general del proceso, Barcelona: Talleres Graficos Ibero Americanos, 1936, p. 55. 
RAMALHO JUNIOR, Elmir Duclerc. Ensaio para uma teoria agnóstica do processo penal. Revista Eletrônica Direito e Política, Programa de Pós-Graduação Stricto Sensu em Ciência Jurídica da UNIVALI, Itajaí, v.10, n.2, $1^{\circ}$ quadrimestre de 2015. Disponível em: www.univali.br/direitoepolitica - ISSN 1980-7791.

alguns casos. Veja-se, por exemplo, que apesar de determinar a reunião de processos nos casos de crimes conexos (art. 79 do CPP), o próprio legislador do CPP abre exceções e permite até mesmo a separação posterior, a critério e por conveniência do juiz, ainda que isso represente um risco de decisões contraditórias no âmbito da justiça criminal.

Em nome dessa aspiração ilusória de coerência, o princípio da unidade da jurisdição acaba por legitimar a sanção penal como forma eficaz e democrática de solução de conflitos, o que não parece compatível com o conteúdo das críticas que já temos levantado sobre o sistema penal, sua seletividade e seu compromisso com processos de dominação e exclusão.

Some-se a isso que, se levarmos a sério as lições da criminologia crítica poderemos concluir, com Zaffaroni, que por trás da distinção entre sanção civil e sanção penal o que há é uma diferença fundamental entre dois modelos de solução de conflitos conhecidos historicamente: um modelo reparador e um modelo punitivo, que embora funcionem com lógicas diametralmente opostas, atuam de maneira cumulativa e superposta na grande maioria dos ordenamentos jurídicos do ocidente.

\section{TEORIA AGNÓSTICA E MÉTODO DE ENSINO DO DIREITO PROCESSUAL PENAL}

As contribuições do pensamento crítico, como já vimos, relaciona, dentre os diversos atores do sistema penal, a própria academia, como agência de reprodução ideológica, responsável, no limite, por produzir o idioma a ser utilizado na comunicação que atravessa todo o tecido sistêmico, o que põe em relevo o inestimável valor estratégico na forma como se ensina a disciplina.

As linhas que seguem, portanto, resultam da nossa reflexão sobre como se constrói (e executa, sobretudo) um plano de curso da disciplina.

Olhando para os modelos disponíveis nesse mercado, e para os índices dos manuais (a partir dos quais se constroem os planos de curso) o que nos parece é 
RAMALHO JUNIOR, Elmir Duclerc. Ensaio para uma teoria agnóstica do processo penal. Revista Eletrônica Direito e Política, Programa de Pós-Graduação Stricto Sensu em Ciência Jurídica da UNIVALI, Itajaí, v.10, n.2, $1^{\circ}$ quadrimestre de 2015. Disponível em: www.univali.br/direitoepolitica - ISSN 1980-7791.

que a própria distribuição dos temas do direito processual penal segue a lógica (mais ou menos arbitrária e irrefletida) e a ordem em que ditos temas aparecem no código: inquérito, ação, ação civil, jurisdição...sentença, recursos, ações, nulidades.

Assim, a construção de uma teoria agnóstica do processo penal reclama, também, um rompimento com esse (mal) hábito.

Por tudo que já dissemos acima, intuímos que um programa de processo penal que esteja comprometido com o Estado Democrático de Direito bem poderia estar composto por três elementos fundamentais, assim delineados:

a) Fundamentos: este seria o momento para a apresentação do referencial teórico, dos princípios que regem a disciplina (bases filosóficas, ou éticopolíticas), e dos conceitos operativos (tecnologia processual) mais importantes (ação, jurisdição, processo, investigação preliminar).

b) Desdobramentos: este seria o "miolo" da disciplina, contemplando temas como prova, competência, prisões, sujeitos processuais, todos eles entendidos como desdobramentos lógicos dos fundamentos. Veja-se, por exemplo, o caso das prisões processuais: a um só tempo desdobramento da jurisdição (ação e processo) cautelar, e do princípio do estado de inocência.

c) Teoria das formas (atos, procedimentos e nulidades) e sistema de impugnação de decisões judiciais (recursos e ações): aqui teríamos o fechamento do sistema. Em suma, num processo que se pretenda garantidor dos direitos fundamentais do ofendido, a observância da base principiológica, no trato com os temas específicos (desdobrados) deve estar assegurada por determinadas formas legais e por uma rígida disciplina de nulidades, reforçada por um bom sistema de impugnação de decisões que assegure uma dupla linha de defesa. 
RAMALHO JUNIOR, Elmir Duclerc. Ensaio para uma teoria agnóstica do processo penal. Revista Eletrônica Direito e Política, Programa de Pós-Graduação Stricto Sensu em Ciência Jurídica da UNIVALI, Itajaí, v.10, n.2, $1^{\circ}$ quadrimestre de 2015. Disponível em: www.univali.br/direitoepolitica - ISSN 1980-7791.

\section{CONSIDERAÇÕES FINAIS}

Como dissemos, o objetivo do presente ensaio era apresentar o estado da arte da pesquisa que estamos empreendendo sobre as condições de possibilidade de uma Teoria Agnóstica do Processo Penal. O último desafio, como vimos, é construir uma ferramenta tecnológica que seja capaz de espelhar esse descompromisso com a legitimação da punição, criando categorias adequadas ao Direito Penal. Em última análise, a técnica deve ter por escopo fazer cumprir, dar efetividade aos princípios de garantia que estão inscritos na Constituição com a finalidade de proteger a liberdade.

Assim, a título de conclusões, apresentamos, sinteticamente, nossas primeiras intuições.

Tais seriam:

a) Se temos consciência da agnosticidade da pena, então a punição não pode nem precisa ser entendida como um direito (jus puniendi) mas como um poder (potestas).

b) Se é assim, a missão do direito processual penal estará limitada à contenção do poder punitivo, o que significa dizer que não pode servir de palco para qualquer pretensão reparadora em face da vítima. Ou bem o processo penal e suas garantias protegem a liberdade, ou bem asseguram a efetividade das pretensões reparadoras da vítima.

c) Se percebemos que a punição radica, em última análise, na irracionalidade ancestral do desejo de vingança, então a vítima deve recuperar o seu protagonismo no processo penal, não para se ver indenizada, mas para dizer se quer ou não quer exercer a sua vingança.

d) Se é assim, a ação penal só poderá ser exercida nos casos em que haja de fato um bem jurídico penalmente tutelado e pertencente a um sujeito concreto de direto. 
RAMALHO JUNIOR, Elmir Duclerc. Ensaio para uma teoria agnóstica do processo penal. Revista Eletrônica Direito e Política, Programa de Pós-Graduação Stricto Sensu em Ciência Jurídica da UNIVALI, Itajaí, v.10, n.2, $1^{\circ}$ quadrimestre de 2015. Disponível em: www.univali.br/direitoepolitica - ISSN 1980-7791.

e) Se temos consciência da função garantidora que deve desempenhar o processo, para que ele não se desvirtue em antecipação da punição, a ação penal deve ser entendida como um aspecto (processual) do próprio poder punitivo, e sujeito, ele mesmo, a certos requisitos.

f) Se é assim, já não faz o menor sentido falar de autonomia e abstração da ação (em face do poder punitivo), nos termos expostos acima.

g) A ação penal precisa, sim, estar vinculada a critérios de legalidade, mas de uma legalidade garantista, que abra a possibilidade de não instauração do processo por questões de conveniência e oportunidade, o que não significa, notese bem, que não deve haver critérios legais e mecanismos de fiscalização institucionais para evitar desvios de finalidade.

h) Por outro lado, as chamadas condições da ação, no seu conjunto, devem ser pensadas sempre à luz da relação custo-benefício do exercício do poder punitivo e, nesses termos, poderiam ser reduzidas a duas: legitimidade; e justa causa, para alcançar não mais apenas a prova indiciária pré-constituída, mas todo e qualquer fator que seja determinante da relação custo $x$ benefício antes referida (absorvendo o interesse de agir, inclusive).

i) Se reconhecemos o processo como uma espécie de antessala da prisão, se com Carnelutti percebemos as suas misérias, se concebemos a punição como um fenômeno que precisa ser contido, inclusive no processo, então já não faz mais sentido falar do processo como relação jurídica, mas à maneira de Goldschmidt, como situação jurídica.

j) De igual modo, o reconhecimento da dimensão punitiva do próprio processo abre espaço para falar de coisa julgada, ainda que o processo tenha sido extinto por razões ditas preliminares ao mérito.

Enfim, estão postas algumas questões que relacionamos apenas como exemplos, e que merecerão, junto com outras, a nossa atenção no momento oportuno, mas que já podem ser compartilhadas e expostas ao debate público. 
RAMALHO JUNIOR, Elmir Duclerc. Ensaio para uma teoria agnóstica do processo penal. Revista Eletrônica Direito e Política, Programa de Pós-Graduação Stricto Sensu em Ciência Jurídica da UNIVALI, Itajaí, v.10, n.2, $1^{\circ}$ quadrimestre de 2015. Disponível em: www.univali.br/direitoepolitica - ISSN 1980-7791.

\section{REFERÊNCIAS DAS FONTES CITADAS}

ABBAGNANO, Nicola. Dicionário de filosofia. 3. ed. São Paulo: Martins Fontes, 1999.

ALCALÁ-ZAMORA Y CASTILLO, Niceto. Estudios de teoría general e historia del proceso. México: Universidad Nacional Autónoma de México (UNAM), 1992. v. 2.

ALVES, Rubem Azevedo. Filosofia da ciência: introdução ao jogo e suas regras. São Paulo: Ars Poética, 1996.

BINDER, Alberto M. Introdução ao direito processual penal. Tradução de Fernando Zani. Rio de Janeiro: Lumen Juris, 2003.

CARVALHO, Salo de. Antimanual de criminologia. 2. ed. Rio de Janeiro: Lumen Juris, 2008.

CHAUÍ, Marilena. Convite à filosofia. 13. ed., 10. impr. São Paulo: Ática, 2009. COUTINHO, Jacinto Nelson de Miranda. A lide e o conteúdo do processo penal. Curitiba: Juruá, 1989.

FERRAJOLI, Luigi. Derecho y razón: teoría del garantismo penal. 3. ed. Madrid: Trotta, 1998.

FOUCAULT, Michel. Vigiar e punir: nascimento da prisão. Tradução de Raquel Ramalhete. 19. ed. Petrópolis: Vozes, 1999.

GOLDSCHIMIDT, James. Teoría general del processo. Barcelona: Talleres Graficos Ibero - Americanos, 1936.

SILVA, Ovidio Araújo Baptista da. Processo e ideologia: o paradigma racionalista. 2. ed. Rio de Janeiro: Forense, 2006.

TAVARES, Juarez. Teorias do delito: variações e tendências. São Paulo: Revista dos Tribunais, 1980. 
RAMALHO JUNIOR, Elmir Duclerc. Ensaio para uma teoria agnóstica do processo penal. Revista Eletrônica Direito e Política, Programa de Pós-Graduação Stricto Sensu em Ciência Jurídica da UNIVALI, Itajaí, v.10, n.2, $1^{\circ}$ quadrimestre de 2015. Disponível em: www.univali.br/direitoepolitica - ISSN 1980-7791.

ZAFFARONI, Eugenio Raúl et al. Direito penal brasileiro: teoria geral do direito penal. Tradução de Nilo Batista; Helena Ferreira. Rio de Janeiro: Revan, 2003.

Submetido em: Março/2015

Aprovado em: Abril/2015 